\title{
Children Born with Congenital Heart Defects and Growth Restriction at Birth: A Systematic Review and Meta-Analysis
}

\author{
Ali Ghanchi ${ }^{1,2}, * \mathbb{D}$, Neil Derridj ${ }^{1,3}$, Damien Bonnet ${ }^{3}$, Nathalie Bertille ${ }^{1}$, Laurent J. Salomon ${ }^{2}$ \\ and Babak Khoshnood ${ }^{1}$ \\ 1 Université de Paris, CRESS, INSERM, INRA, F-75004 Paris, France; neil.derridj@inserm.fr (N.D.); \\ nathalie.bertille@inserm.fr (N.B.); babak.khoshnood@inserm.fr (B.K.) \\ 2 Service d'Obstétrique-Maternité, chirurgie médecine et imagerie fœtales, APHP, \\ Hôpital Necker Enfants Malades, F-75015 Paris, France; laurent.salomon@aphp.fr \\ 3 Department of Pediatric Cardiology, M3C-Necker, APHP, Hôpital Necker-Enfants Malades, \\ F-75015 Paris, France; damien.bonnet@aphp.fr \\ * Correspondence: ali.ghanchi@aphp.fr
}

Received: 30 March 2020; Accepted: 20 April 2020; Published: 28 April 2020

\begin{abstract}
Newborns with congenital heart defects tend to have a higher risk of growth restriction, which can be an independent risk factor for adverse outcomes. To date, a systematic review of the relation between congenital heart defects (CHD) and growth restriction at birth, most commonly estimated by its imperfect proxy small for gestational age (SGA), has not been conducted. Objective: To conduct a systematic review and meta-analysis to estimate the proportion of children born with CHD that are small for gestational age (SGA). Methods: The search was carried out from inception until 31 March 2019 on Pubmed and Embase databases. Studies were screened and selected by two independent reviewers who used a predetermined data extraction form to obtain data from studies. Bias was assessed using the Critical Appraisal Skills Programme (CASP) checklist. The database search identified 1783 potentially relevant publications, of which 38 studies were found to be relevant to the study question. A total of 18 studies contained sufficient data for a meta-analysis, which was done using a random effects model. Results: The pooled proportion of SGA in all CHD was $20 \%(95 \%$ CI $16 \%-24 \%)$ and $14 \%(95 \%$ CI $13 \%-16 \%)$ for isolated CHD. Proportion of SGA varied across different CHD ranging from 30\% (95\% CI 24\%-37\%) for Tetralogy of Fallot to 12\% (95\% CI $7 \%-18 \%$ ) for isolated atrial septal defect. The majority of studies included in the meta-analysis were population-based studies published after 2010. Conclusion: The overall proportion of SGA in all CHD was 2-fold higher whereas for isolated CHD, 1.4-fold higher than the expected proportion in the general population. Although few studies have looked at SGA for different subtypes of CHD, the observed variability of SGA by subtypes suggests that growth restriction at birth in CHD may be due to different pathophysiological mechanisms.
\end{abstract}

Keywords: congenital heart defects; small for gestational age; systematic review; meta-analysis; population-based study

\section{Introduction}

Congenital heart defects (CHD) are the most common group of congenital anomalies with a live birth prevalence of 8.2 per 1000 births in Europe [1]. Despite considerable progress in medical and surgical management of CHD, they remain the most important cause of infant death by malformation. One study suggested that there were approximately 260,000 deaths due to CHD in 2017 [2]. However, 
the survival rate is much higher in high resource countries and a recent review found that $85 \%$ of children with CHD reach adulthood [3].

Growth restriction at birth, often measured by its imperfect proxy small for gestational age is an important risk factor for perinatal mortality, morbidity, and long-term adverse outcomes, including an increased risk of diabetes, hypertension, and cardiovascular disease later in life.

Therefore, growth restriction in a newborn with a CHD may represent a "double jeopardy" with risks related to $\mathrm{CHD}$ combined with those associated with growth restriction. Moreover, differences in the proportion of CHD subtypes with growth restriction may provide clues about possible pathophysiological mechanisms of the relation between growth restriction and CHD.

To date, no systematic review of the relation between CHD and growth restriction at birth has been conducted. The objective of our study was to conduct a systematic review and meta-analysis of the relation between growth restriction at birth and CHD.

\section{Methods}

This study is reported in accordance to Preferred Reporting Items for Systematic Review and Meta-analyses (PRISMA) guidelines [4]. The review protocol was registered on the PROSPERO: International Prospective Register of Systematic Reviews website [5]. As data sources originated from previously published studies in the public domain, ethical approval for this study was not requested [6].

\subsection{Search Strategy}

A comprehensive literature search was carried out on Pubmed/Medline and Embase databases with the assistance of a specialized documentalist. Medical Subject Headings (MeSH)/Medical Embase Medical Headings (EMTREE) and keywords that included different synonyms for CHD, CHD subtypes, small for gestational age (SGA), fetal growth restriction (FGR)/intrauterine growth retardation (IUGR) and low birth weight were combined together using Boolean operators. The search was carried out from inception until 31/03/2019 and no language preferences were applied. A manual search of references in included articles was carried out to complete the search.

\subsection{Study Selection}

Titles and abstracts of retrieved studies were screened independently by two blinded reviewers (AG and ND) using Rayaan web application [7]. Excluded articles were about CHD and low birth weight only, conference abstracts, CHD and single umbilical artery, absence of SGA data, matched case control studies, use of estimated fetal weight from ultrasound data, and SGA outcomes in the offspring of women born with CHD.

\subsection{Data Extraction}

A predetermined data extraction form was designed and used independently by the two reviewers (AG and ND). Extracted data for each study included study characteristics, object of study, SGA outcomes, data sources, exclusion criteria, and SGA proportions. Authors of studies were contacted to request further information or clarification of results.

\subsection{Evaluation of Bias}

The Critical Appraisal Skills Programme (CASP) cohort study checklist evaluated the risk of bias in studies included in this review [8]. The checklist contains 12 questions divided into three sections that enable a structured approach to finding evidence, determine possible sources of bias, and evaluate internal and external validity of each study. We adapted this checklist to our study question paying particular attention to selection and measurement biases. 
Throughout the entire process (article selection, data extraction, and evaluation of bias) discrepancies were resolved through end result discussion. Any further disagreements between the two reviewers (AG and ND) were resolved by a third reviewer (BK).

\subsection{Definitions}

CHD was defined as children born with structural heart defect and excluded patent ductus arteriosus, cardiac tumors, cardiomyopathies, and arrhythmias. Isolated CHD was defined as CHD not associated with chromosomal anomalies, malformations from other systems or syndromes. Due to data availability, we used SGA as an imperfect measure of growth restriction at birth. We used the consensual definition of SGA, defined as birthweight $<10$ th percentile according to gestational age and compared to a standard population [9]. Studies were grouped according to birthweight percentile cut-off rather than labels assigned by the different authors.

\subsection{Statistical Analysis}

A meta-analysis of pooled proportions (with their 95\% confidence intervals) was carried out using a random effects model with inverse variance weighting, using the Simonian and Laird method $[10,11]$. Freeman-Tukey double arcsine transformation was used to limit the effects of over-weighting caused by studies with a variance close to zero for estimating the confidence intervals for the pooled estimate $[10,11]$. The $\mathrm{I}^{2}$ statistic assessed statistical heterogeneity between groups. Principal analysis concerned all/isolated CHD using the SGA defined using the 10th percentile cutoff threshold. Additional analyses were conducted for CHD subtypes and for severe SGA using the 3rd percentile. Sensitivity analysis was carried by restricting the analysis to only population-based studies. The meta-analysis was performed using STATA 12.1 software (StataCorp LP., College Station, TX, USA). We considered $p$-values $<0.05$ as statistically significant.

\section{Results}

The database search identified 1783 potentially relevant publications of which 72 articles were assessed for eligibility. An additional two studies were found through hand searching of reference lists $[12,13]$. In total 38 studies were found to be relevant to the study question of which 18 citations contained sufficient data for a meta-analysis (Figure 1). 

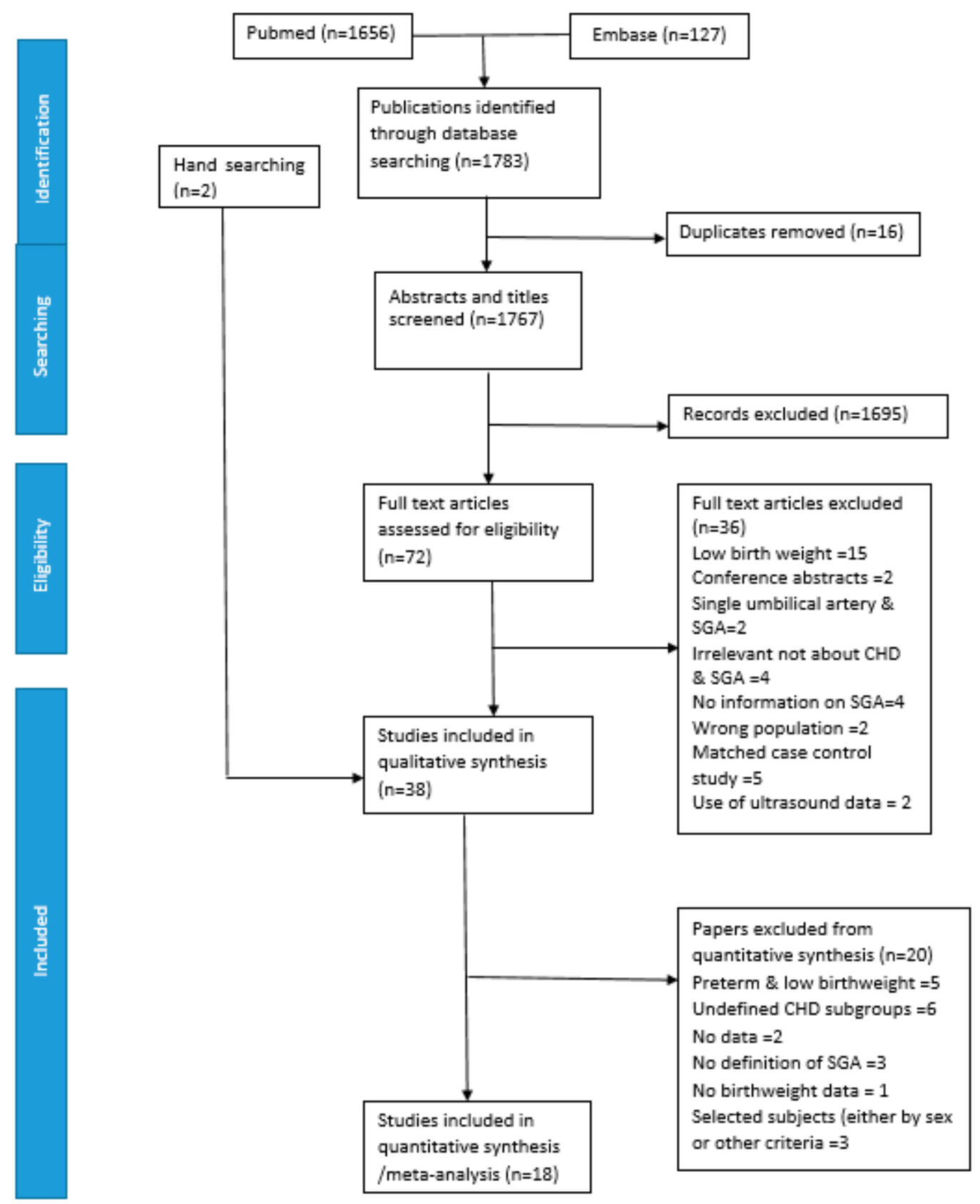

Figure 1. Flow chart to indicate the selection of studies.

\subsection{Study Characteristics}

Characteristics of the studies according to year of publication, country and objective of the study are shown in Table 1. Publication years ranged from 1972 to 2018 and 23 (60.5\%) studies were published between 2010 and 2019. Sample sizes of patients with CHD ranged from 16 to 99,786. Twenty-six studies (68.5\%) were based on US cohorts. The reference populations varied greatly based on geographical location and the year of study. Overall, 19 different reference populations were cited. The most frequent was growth curve by Alexander et al., which was used in six American studies while eight $(21 \%)$ studies did not state which reference population was used. 
Table 1. Number of citations according to different study characteristics.

\begin{tabular}{|c|c|c|}
\hline Characteristics of Study & Number of Publications & Number of Publications in MA \\
\hline Year of Publication $(n=38)$ & & $(n=18)$ \\
\hline 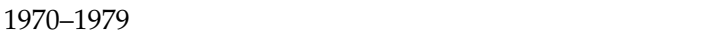 & $3(7.9 \%)$ & $2(11.1 \%)$ \\
\hline 1980-1989 & $1(2.6 \%)$ & $1(5.6 \%)$ \\
\hline 1990-1999 & $3(7.9 \%)$ & $2(11.1 \%)$ \\
\hline 2000-2009 & $8(21.1 \%)$ & $6(33.3 \%)$ \\
\hline 2010-2019 & $23(60.5 \%)$ & $7(38.9 \%)$ \\
\hline Country $(n=38)$ & & $(n=18)$ \\
\hline USA & $26(68.5 \%)$ & $14(77.8 \%)$ \\
\hline Sweden & $4(10.5 \%)$ & $1(5.6 \%)$ \\
\hline China & $3(8 \%)$ & $1(5.6 \%)$ \\
\hline Italy & $1(2.6 \%)$ & 0 \\
\hline France & $1(2.6 \%)$ & 0 \\
\hline Chili & $1(2.6 \%)$ & 0 \\
\hline UK & $1(2.6 \%)$ & $1(5.6 \%)$ \\
\hline Definition of SGA according to percentile $(n=38)$ & & $(n=18)$ \\
\hline 10th percentile (consensus definition of SGA) & $22(57.9 \%)$ & $14(77.8 \%)$ \\
\hline 3rd percentile & $7(18.4 \%)$ & $4(22.2 \%)$ \\
\hline Undefined percentile & $9(23.7 \%)$ & 0 \\
\hline Consensus definition of SGA: 10 th percentile: $(n=38)$ & & $(n=14)$ \\
\hline No comparison & $6(27.2 \%)$ & $4(28.6 \%)$ \\
\hline According to gestational age and sex & $6(27.3 \%)$ & $4(28.6 \%)$ \\
\hline According to gestational age & $4(18.2 \%)$ & $3(21.4 \%)$ \\
\hline According to gestational age, sex and race & $3(13.7 \%)$ & $1(7.1 \%)$ \\
\hline According to gestational age and race & $2(9.1 \%)$ & $2(14.3 \%)$ \\
\hline $\begin{array}{l}\text { According to gestational age, race, sex, and single or } \\
\text { multiple gestation }\end{array}$ & $1(4.6 \%)$ & 0 \\
\hline Birthweight data provided for SGA & $35(92.1 \%)$ & $18(100 \%)$ \\
\hline Characteristics of Study & Number of Publications & Number of Publications in MA \\
\hline SGA 1st aim of study & $17(44.7 \%)$ & $13(72.2 \%)$ \\
\hline \multicolumn{3}{|l|}{ CHD } \\
\hline All & 23 & 8 \\
\hline Isolated & 10 & 7 \\
\hline \multicolumn{3}{|l|}{ CHD subtype } \\
\hline HLHS & 10 & 8 \\
\hline ToF & 10 & 7 \\
\hline CoAo & 8 & 7 \\
\hline TGV & 7 & 7 \\
\hline AVSD & 7 & 7 \\
\hline ASD & 7 & 6 \\
\hline TA & 3 & 3 \\
\hline CAT & 3 & 3 \\
\hline
\end{tabular}

Legend: MA—meta-analysis; SGA—small for gestational age; CHD—congenital heart defect; HLHS—hypoplastic left heart syndrome; ToF-Tetralogy of Fallot; VSD—ventricular septal defect; CoAo-coarctation of the aorta; TGV—-transposition of great vessels; AVSD—atrioventricular septal defect; ASD—atrial septal defect; TA—tricuspid atresia; CAT—common truncus arteriosus.

Of the 38 studies included in the systematic review, $22(57.9 \%)$ used birthweight $<10$ th percentile) for definition of SGA; 17 (44.7\%) studies were designed specifically to study SGA and CHD as their primary objective. Six studies (27.2\%) did not report explicitly the use of gestational age or a reference population in their definition of SGA, whereas six studies (27.2\%) studies considered gender in addition to gestational age in the definition of SGA (Table 1). Three (7.9\%) studies used the term FGR even though the actual outcome was SGA.

Twenty-three (60.5\%) studies comprised all CHD and 10 (26.3\%) isolated CHD only. In addition, 12 specific subgroups were studied with the majority of studies on hypoplastic left heart syndrome (HLHS) and Tetralogy of Fallot (ToF) (10 publications). 
3.2. Proportion of SGA in All CHD, Isolated CHD, and Subgroups Reported by Individual Studies

As shown in Table 2, the proportions of SGA in all, isolated, and subgroups of CHD varied greatly across the studies in the systematic review. It was found that four (10.5\%) studies on isolated CHD reported same proportion of SGA i.e., $15 \%$. The proportion of SGA varied between 3\% and 37\% for HLHS $8 \%$ and $67 \%$ for ToF and $10 \%$ and $40 \%$ for ventricular septal defects and $5 \%$ and $57 \%$ for coarctation of the aorta (CoAo).

Some studies were restricted to preterm births or very low birth weight infants even though by far most studies included all gestational ages. Certain studies included a selected set of newborns with CHD, e.g., those operated for critical CHD. Only one study examined SGA for isolated CHD subgroups [14]. 
Table 2. Summary of key characteristics of individual studies.

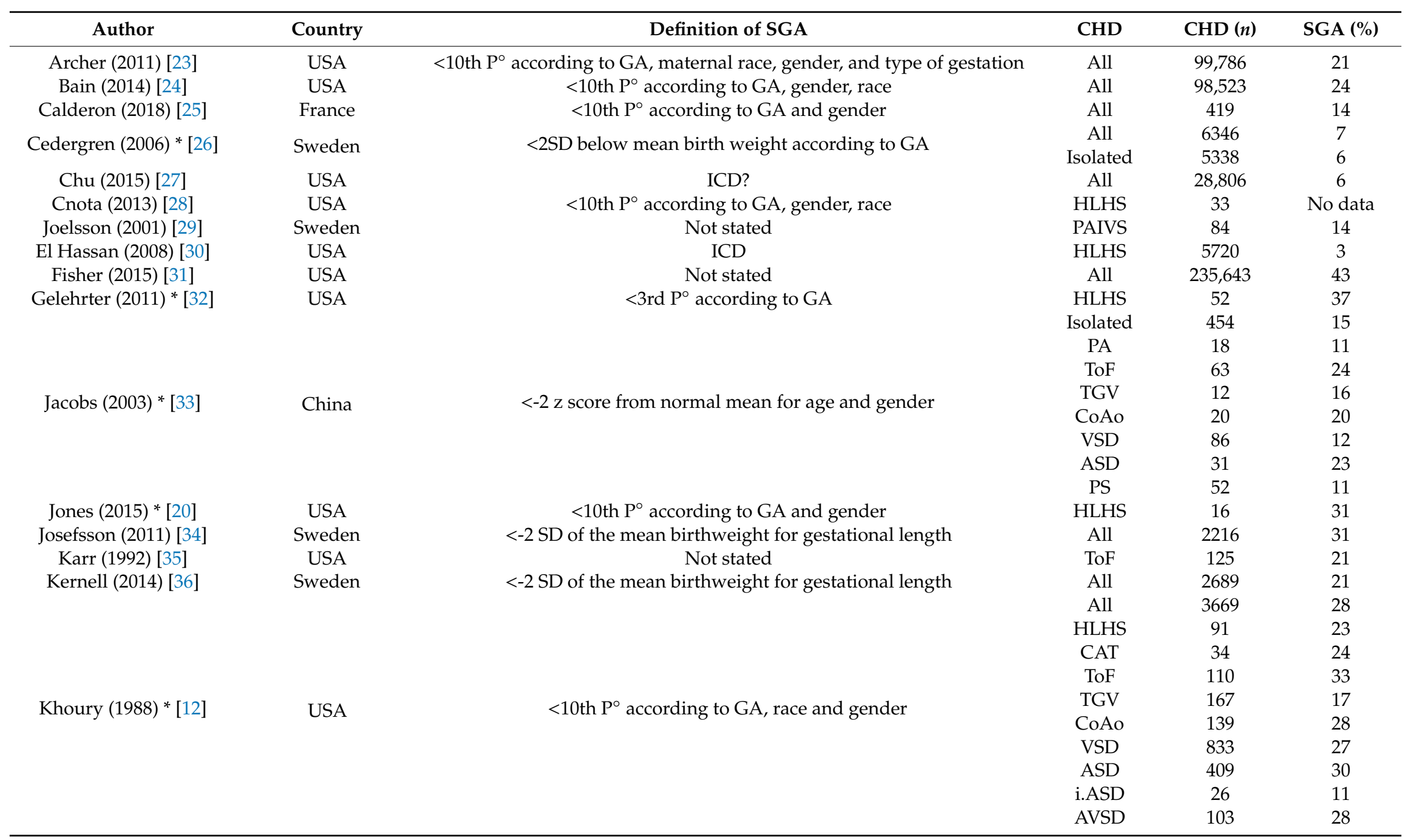


Table 2. Cont.

\begin{tabular}{|c|c|c|c|c|c|}
\hline Author & Country & Definition of SGA & CHD & CHD $(n)$ & SGA (\%) \\
\hline & & & Isolated & 843 & 15 \\
\hline & & & ToF & 81 & 26 \\
\hline & & & TGV & 60 & 15 \\
\hline \multirow{4}{*}{ Kramer $(1990) *[37]$} & & & CoAo & 69 & 13 \\
\hline & & & VSD & 236 & 13 \\
\hline & & & ASD & 70 & 17 \\
\hline & & & All & 37 & 43 \\
\hline \multirow{7}{*}{ Levin (1975) [38] } & & & AoA & 3 & 70 \\
\hline & & & All & 2178 & 6 \\
\hline & & & HLHS & 163 & 6 \\
\hline & & & TA & 64 & 5 \\
\hline & & & TAPVR & 58 & 3 \\
\hline & & & ToF & 156 & 7 \\
\hline & & & TGV & 217 & 2 \\
\hline \multirow[t]{6}{*}{ Levy $(1978) *$ [39] } & USA & $<2 \mathrm{SD}$ below mean birth weight of control group & AS & 43 & 2 \\
\hline & & & CoAo & 136 & 6 \\
\hline & & & ASD & 59 & 8 \\
\hline & & & AVSD & 107 & 8 \\
\hline & & & PS & 81 & 5 \\
\hline & & & PAIVS & 64 & 6 \\
\hline Li (2009) [21] & China & Not stated & All & 274 & 5 \\
\hline Lupo (2011) [40] & USA & $<10$ th $\mathrm{P}^{\circ}$ according to GA and gender & Ebstein & 175 & 19 \\
\hline \multirow[t]{5}{*}{$\operatorname{Malik}(2007) *[16]$} & USA & $<10$ th $\mathrm{P}^{\circ}$ according to GA and gender & Isolated & 3395 & 15 \\
\hline & & & All & 9645 & 19 \\
\hline & & & HLHS & 283 & 23 \\
\hline & & & CAT & 112 & 25 \\
\hline & & & ToF & 602 & 26 \\
\hline \multirow[t]{5}{*}{ Nembhard $(2009) *[41]$} & USA & $<10$ th $\mathrm{P}^{\circ}$ using race specific growth curve & Ebstein & 61 & 15 \\
\hline & & & TGV & 472 & 20 \\
\hline & & & CoAo & 592 & 20 \\
\hline & & & VSD & 5528 & 17 \\
\hline & & & ASD & 467 & 28 \\
\hline
\end{tabular}


Table 2. Cont.

\begin{tabular}{|c|c|c|c|c|c|}
\hline Author & Country & Definition of SGA & CHD & CHD (n) & SGA $(\%)$ \\
\hline \multirow{2}{*}{ Nembhard $(2007) *[17]$} & \multirow{2}{*}{ USA } & \multirow{2}{*}{$<10$ th $\mathrm{P}^{\circ}$ using race specific growth curve } & All & 12,964 & 16 \\
\hline & & & Isolated & 10,870 & 13 \\
\hline Oyarzún (2018) [22] & Chile & Not stated & Isolated & 46 & 26 \\
\hline Polito (2013) [43] & Italy & $<3 \mathrm{rd} \mathrm{P}^{\circ}$ & All & 70 & 17 \\
\hline \multirow{5}{*}{ Reynolds (1972)* [13] } & \multirow{5}{*}{ USA } & \multirow{5}{*}{$<10$ th $\mathrm{P}^{\circ}$ according to GA } & All & 433 & 14 \\
\hline & & & AS & 21 & 38 \\
\hline & & & Isolated & 1299 & 12 \\
\hline & & & CAT & 113 & 18 \\
\hline & & & ToF & 119 & 7 \\
\hline \multirow{6}{*}{ Rosenthal $(1991) *[14]$} & \multirow{6}{*}{ USA } & \multirow{6}{*}{$<10$ th $\mathrm{P}^{\circ}$ according to GA } & Ebstein & 57 & 5 \\
\hline & & & TGV & 103 & 10 \\
\hline & & & CoAo & 470 & 11 \\
\hline & & & VSD & 130 & 12 \\
\hline & & & ASD & 44 & 18 \\
\hline & & & PS & 167 & 14 \\
\hline Sochet (2013) [44] & USA & $<10$ th $\mathrm{P}^{\circ}$ according to GA & All & 230 & 25 \\
\hline \multirow[t]{5}{*}{ Story $(2015) *[46]$} & \multirow[t]{5}{*}{ UK } & \multirow[t]{5}{*}{$<10$ th $\mathrm{P}^{\circ}$} & Isolated & 308 & 16 \\
\hline & & & All & 753 & 21 \\
\hline & & & HLHS & 261 & 19 \\
\hline & & & TA & 38 & 16 \\
\hline & & & CAT & 28 & 21 \\
\hline \multirow{6}{*}{ Swenson $(2012) *[47]$} & \multirow{6}{*}{ USA } & \multirow{6}{*}{$<10$ th $\mathrm{P}^{\circ}$} & DROV & 54 & 24 \\
\hline & & & TAPVR & 35 & 26 \\
\hline & & & ToF & 70 & 36 \\
\hline & & & TGV & 181 & 13 \\
\hline & & & IAA & 44 & 36 \\
\hline & & & AVSD & 25 & 32 \\
\hline
\end{tabular}


Table 2. Cont.

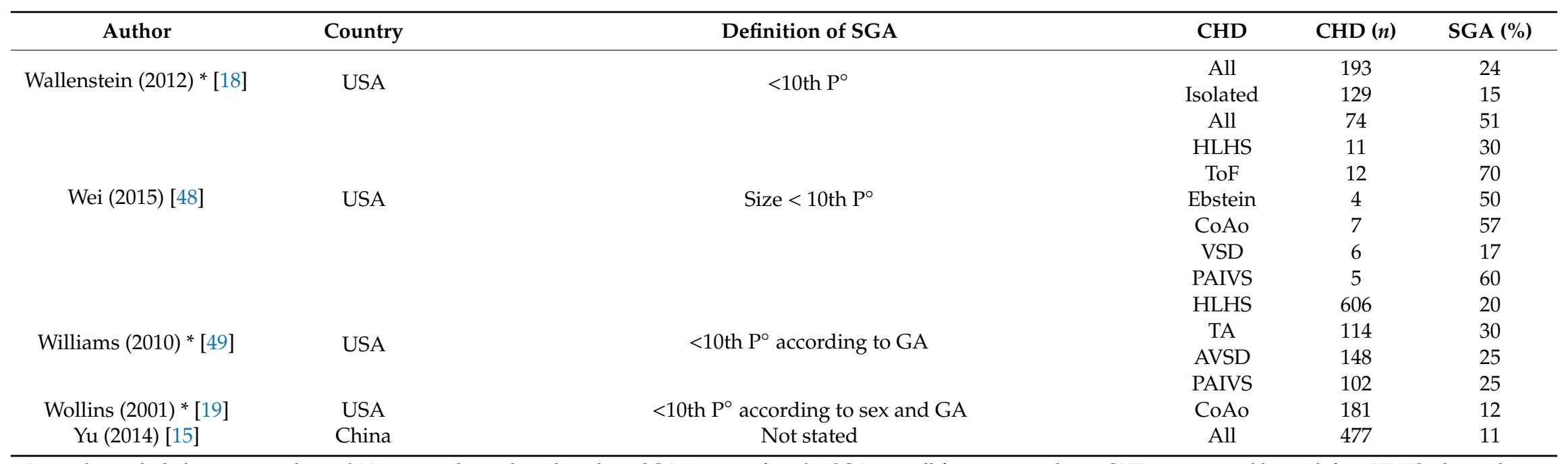

Legend: * included in meta-analysis. § Not a population-based study. $\sigma$ SGA 1st aim of study. SGA—small for gestational age; CHD—congenital heart defect; HLHS—hypoplastic left heart syndrome; ToF-Tetralogy of Fallot; VSD—ventricular septal defect; CoAo—coarctation of the aorta; TGV—transposition of great vessels; AVSD—atrioventricular septal defect; ASD—atrial septal defect; i.ASD—isolated atrial septal defect; TA—-tricuspid atresia; CAT—common truncus arteriosus; PAIVS—-pulmonary atresia intact ventricular septum; TAPVR—-total anomalous pulmonary venous return; DORV—double outlet right ventricle; IAA—interrupted aortic arch; AoA—aortic atresia; PS—pulmonary stenosis; AS—aortic stenosis; $\mathrm{P}^{\circ}$ - percentile; $\mathrm{GA}$ - gestational age; $\mathrm{SD}$ - standard deviation; ICD—international classification of diseases. 


\subsection{Evaluation of Bias}

Studies were evaluated for bias using a modified CASP checklist. Yu et al. was omitted because we could not obtain the full article [15]. All studies addressed a clearly focused issue, however the quality of studies regarding other criteria in the checklist varied greatly. In particular, most studies were to some extent subject to selection and measurement bias, especially with regards to diagnosis of CHD using a validated diagnostic method.

Few studies took into consideration the effects of confounding factors (e.g., parity, ethnicity, maternal disease, maternal smoking, etc.). Four studies were found to have a lower risk of bias [15-18], whereas five others were deemed to have a higher risk of bias [12,19-22]. Confidence intervals (CI) for SGA proportions were not provided in any study. Notwithstanding differences in geographic locations and reference populations, external validity criterion was met for most studies as they were population-based.

\subsection{Meta-Analysis}

Of the 38 articles in the systematic review, we used $18(47.4 \%)$ in the meta-analysis. The reasons for excluding studies from the meta-analysis are detailed in Figure 1. These included studies of low birth weight and preterm newborns only, unclear definition or of CHD subgroups included, absence of data on birth weight or clear definition of SGA, and studies limited to one gender only.

The pooled proportion of SGA in all CHD was 20\% (95\% CI 16-24\%) and for isolated CHD $14 \%$ (95\% CI 13-16\%) (Figure 2). Limiting the meta-analysis only to population-based studies did not change the results appreciably. Based on two studies that used the 3rd percentile, the proportion of severe SGA for all CHD was $6 \%(95 \%$ CI 6-7\%).

\begin{tabular}{|c|c|c|c|}
\hline Study & & Proportion SGA $(95 \% \mathrm{CI})$ & Weight $(\%$ \\
\hline \multicolumn{4}{|l|}{ All CHD } \\
\hline Reynolds (1972) ${ }^{[13]}$ & & $0.14(0.11,0.18)$ & 19.41 \\
\hline Khoury (1988) ${ }^{[21]}$ & $\rightarrow$ & $0.27(0.25,0.29)$ & 21.28 \\
\hline Nembhard (2007) ${ }^{[17]}$ & $\rightarrow$ & $0.16(0.15,0.16)$ & 22.52 \\
\hline Nembhard (2009) $)^{[41]}$ & & $0.19(0.19,0.20)$ & 22.44 \\
\hline Wallenstein (2012) ${ }^{[18]}$ & & $0.24(0.18,0.30)$ & 14.35 \\
\hline Subtotal $\left(I^{2}=97.5 \% p=0.00\right)$ & & $0.20(0.16,0.24)$ & 100.00 \\
\hline \multicolumn{4}{|l|}{ Isolated CHD } \\
\hline Kramer (1990) [37] & $\rightarrow$ & $0.15(0.13,0.18)$ & 20.03 \\
\hline Malik (2007) ${ }^{[16]}$ & 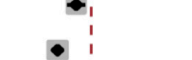 & $0.15(0.14,0.16)$ & 29.55 \\
\hline Nembhard (2007) ${ }^{[17]}$ & $\rightarrow:$ & $0.13(0.12,0.13)$ & 33.46 \\
\hline Wallenstein (2012) ${ }^{[18]}$ & $\rightarrow$ & $0.15(0.09,0.22)$ & 5.98 \\
\hline Story $(2015)^{[46]}$ & $\Delta !$ & $0.16(0.12,0.20)$ & 10.97 \\
\hline Subtotal $\left(I^{2}=74 \% p=0.00\right)$ & 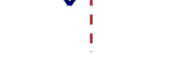 & $0.14(0.13,0.16)$ & 100.00 \\
\hline \multirow[t]{2}{*}{$\begin{array}{l}\text { Overall heterogeneity } \\
\text { between groups } \\
\left(I^{2}=97.5 \% \text { p }=0.00\right)\end{array}$} & $\diamond$ & & \\
\hline & $\begin{array}{lll}0.1 & 0.2 & 0.3 \\
\end{array}$ & 1 & \\
\hline
\end{tabular}

Figure 2. Forest plot of the meta-analysis of proportions of small for gestational age (SGA) in all and isolated congenital heart defects (CHD) according to 10th percentile cutoff threshold. 
Table 3 illustrates the results of meta-analysis for subgroups of CHD. Genetic and other anomalies were not explicitly excluded in the studies reporting on subgroups of CHD. Pooled proportion of SGA was $30 \%$ for ToF, $21 \%$ for HLHS, and $17 \%$ for transposition of great vessels (TGV). The proportion of SGA was lowest for isolated atrial septal defects (ASD) with a proportion of $12 \%$.

Table 3. Meta-analysis of proportions of SGA in different CHD subgroups (including genetic anomalies/syndromes) using the 10th percentile cutoff threshold.

\begin{tabular}{|c|c|c|c|c|}
\hline Subgroup & Author & \multicolumn{2}{|c|}{ Pooled Proportion $(95 \% \mathrm{CI})$} & $\%$ Weight \\
\hline \multicolumn{5}{|l|}{ HLHS } \\
\hline \multirow[t]{5}{*}{ Total pooled result } & & 21 & $(19-23)$ & \\
\hline & Khoury (1988) [12] & 23 & $(15-33)$ & 7.36 \\
\hline & Nembhard (2009) [41] & 23 & $(18-28)$ & 22.81 \\
\hline & Williams (2010) [49] & 20 & $(17-24)$ & 48.79 \\
\hline & Swenson (2012) [47] & 19 & $(15-24)$ & 21.04 \\
\hline \multicolumn{5}{|l|}{ ToF } \\
\hline \multirow[t]{4}{*}{ Total pooled result } & & 30 & $(24-37)$ & \\
\hline & Khoury (1988) [12] & 34 & $(25-43)$ & 29.05 \\
\hline & Nembhard (2009) [41] & 26 & $(23-30)$ & 48.18 \\
\hline & Swenson (2012) [47] & 36 & $(25-48)$ & 22.77 \\
\hline \multicolumn{5}{|l|}{ TGV } \\
\hline \multirow[t]{4}{*}{ Total pooled result } & & 17 & $(13-22)$ & \\
\hline & Khoury (1988) [12] & 17 & $(11-23)$ & 28.79 \\
\hline & Nembhard (2009) [41] & 20 & $(17-24)$ & 41.34 \\
\hline & Swenson (2012) [47] & 13 & $(8-18)$ & 29.87 \\
\hline \multirow{4}{*}{$\begin{array}{c}\text { VSD } \\
\text { Total pooled result }\end{array}$} & & & & \\
\hline & & 19 & $(18-20)$ & \\
\hline & Khoury (1988) [12] & 27 & $(24-31)$ & 13.1 \\
\hline & Nembhard (2009) [41] & 17 & $(16-19)$ & 86.9 \\
\hline \multirow{4}{*}{$\begin{array}{c}\text { CoAo } \\
\text { Total pooled result }\end{array}$} & & & & \\
\hline & & 22 & $(19-25)$ & \\
\hline & Khoury (1988) [12] & 28 & $(21-36)$ & 19.06 \\
\hline & Nembhard (2009) [41] & 20 & $(17-24)$ & 80.94 \\
\hline \multicolumn{5}{|l|}{ AVSD } \\
\hline \multirow[t]{4}{*}{ Total pooled result } & & 27 & $(21-32)$ & \\
\hline & Khoury (1988) [12] & 28 & $(20-38)$ & 37.3 \\
\hline & Williams (2010) [49] & 25 & $(18-33)$ & 53.51 \\
\hline & Swenson (2012) [47] & 32 & $(15-54)$ & 9.19 \\
\hline \multirow{4}{*}{$\begin{array}{c}\text { TA } \\
\text { Total pooled result }\end{array}$} & & & & \\
\hline & & 27 & $(21-35)$ & \\
\hline & Williams (2010) [49] & 30 & $(22-39)$ & 74.84 \\
\hline & Swenson (2012) [47] & 21 & $(10-37)$ & 25.16 \\
\hline \multirow{5}{*}{$\begin{array}{c}\text { CAT } \\
\text { Total pooled result }\end{array}$} & & & & \\
\hline & & 23 & $(17-30)$ & \\
\hline & Khoury (1988) [12] & 24 & $(11-41)$ & 19.66 \\
\hline & Nembhard (2009) [41] & 25 & $(17-34)$ & 64.1 \\
\hline & Swenson (2012) [47] & 18 & $(6-37)$ & 16.24 \\
\hline
\end{tabular}

Legend: HLHS—hypoplastic left heart syndrome; ToF-Tetralogy of Fallot; VSD—ventricular septal defect; CoAo-coarctation of the aorta; TGV - transposition of great vessels; AVSD—atrioventricular septal defect; TA-tricuspid atresia; CAT—common truncus arteriosus. 


\section{Discussion}

\subsection{Main Findings and Interpretations}

This systematic review and meta-analysis found 38 articles that studied the association between SGA and CHD. The pooled proportion of SGA for all CHD was 20\% and for isolated CHD 14\%. Given the definition of SGA as the 10th percentile, these results suggest that overall, newborns with CHD have a two-fold greater risk of SGA compared to its theoretical value and those with isolated CHD a 1.4-fold higher risk of SGA. Estimates of SGA in the general population in developed countries are also considerably lower than the pooled proportions in our meta-analysis [50,51]. There was a great deal of variability in the proportion of SGA for different CHD. Tetralogy of Fallot had the highest proportion of SGA whereas isolated ASD had the lowest proportion of SGA. The range of SGA proportions across studies was highly variable for CHD, isolated CHD, or given subgroups of CHD in the 38 studies included in the systematic review. However, this variability decreased substantially for the 18 studies included in the meta-analysis.

Overall, approximately $20 \%-30 \%$ of CHD are due to known chromosomal, genetic, or other anomalies [52,53]. Some of these anomalies, e.g., Down Syndrome, Turner Syndrome may in turn be associated with growth restrictions. Indeed, isolated CHD had a substantially lower proportion of SGA. The issue of associated anomalies complicates the interpretation of differences in subgroups of CHD as they may be more (ToF) or less (HLHS or CoA) associated with other anomalies.

The higher proportion of SGA in newborns with CHD may be caused either by the CHD itself and/or by a common etiological factor (maternal, fetal, placental) that can cause both CHD and growth restriction $[12,16,52,54]$.

With regards to the theory that CHD causes SGA, a number of authors suggest that alterations in fetal hemodynamics and oxygen saturation due to CHD are the root cause of this association $[12,14,16,51]$. Differences in SGA proportions according to CHD subtypes that we identified in this review support this hypothesis with the proportions of SGA varying from $22 \%$ for CoA to $12 \%$ in isolated ASD. Wallenstein et al. hypothesized that reduced ventricular function decreases cardiac output resulting in stunted fetal growth [18]. Our findings of increased SGA in HLHS (21\%) are consistent with this mechanism. Story et al. maintained that decreased oxygenation in the aortic arch reduces cerebral perfusion and thus causes SGA [46]. Our findings of increased proportions of SGA in transposition of great arteries (TGA) (17\%) may be at least in part explained by this mechanism. Sun et al. also found that decreased oxygen consumption is associated with smaller brain sizes in children with CHD [55].

Several authors have hypothesized that the association between SGA and CHD is caused by one or more common etiological factors (maternal, placental, fetal, and/or environmental) that result in both CHD and SGA $[20,54]$. Malik et al. have proposed that smoking may contribute to a common etiological pathway for CHD and SGA [56]. Although 33 studies (86\%) included in our review provided data on maternal smoking only four $(11 \%)$ took this into consideration in their statistical analysis $[14,18,19,26]$. Cedergren and Kallen theorized that disturbed placentation caused by abnormal trophoblastic growth in early pregnancy results in both SGA and CHD [26]. While, Jones et al. argued that placental insufficiency is the common causal pathway for HLHS [20]. They asserted that placental insufficiency reduces angiogenesis and villous tree maturation of the placenta, thereby reducing the surface area for gaseous and nutritional exchanges. As a result, SGA is induced directly and indirectly by nutritional deficiency. Their observations of increased placental leptin secretion led them to speculate that a predisposition for HLHS is the result of some kind of compensatory mechanism. Nevertheless, the effect of leptin in myocardial hypertrophy is debatable in the literature [57].

In addition to the two possible physiopathological mechanisms previously discussed, Spiers et al. proposed another, even if a minority position, hypothesis in the literature [12,14,46,58] According to Spiers et al., early FGR during cardiogenesis may result in CHD; in other words, SGA may be the cause of CHD [46,58]. Despite the fact that early FGR is very difficult to diagnose, five authors in this review made reference to this theory to account for the genetic anomalies and syndromes that are associated 
with CHD. They used this theory to explain that an intrinsic disturbance in fetal growth could provide a predisposition for $\mathrm{CHD}$. However, to our knowledge little evidence exists to corroborate this theory.

In general, our results raise several questions about the possible underlying mechanisms of the association between SGA and CHD. Few studies were designed to examine this association specifically or to investigate different mechanisms that may explain the association between CHD and SGA. Moreover, the roles of confounding, intermediate (mediating) variables, and possible interactions in the causal pathway(s) between CHD and SGA have not been adequately studied. For example, the role of maternal age, if any, is unclear. While it is well known that maternal age (and parity) are associated with SGA, whether or not maternal age (or parity) in and of itself are risk factors for CHD is not known. Previous studies have provided conflicting results about the possible association between maternal age and CHD even if maternal age is known to be associated with SGA [3,59-62].

The genetic mechanisms potentially related to the association between CHD and SGA appear to be the result of complex, multifactorial interactions between genetics, epigenetics, and the environment that are poorly understood [61-63]. Certain specific isolated CHD subtypes may be caused by point mutations to transcription factors of specific genes (e.g., IRX4 results in VSD) that affect cardiogenesis. The expression of genes either directly (through methylation or other mechanisms) or indirectly via environmental exposure has been associated with CHD. DNA methylation was one of the first epigenetic mechanisms to be associated with CHD e.g., aberrant methylation of NKX2-5 and HAND1 genes has been observed to result in TOF [62]. A hypomethylative state of certain maternal genes may result in CHD being inherited in the offspring [64,65]. Monteagudo-sanchez et al. found that aberrant methylation of placental genes resulted in FGR although to our knowledge no study has yet to investigate hypomethylation of genes that cause both CHD and SGA [64]. Alternatively, chromatin remodeling and histone modification may also result in CHD epigenesis e.g., inactivation of deacetylases 5 and 9 are a feature of lethal VSD [61,62]. Small non-coding RNA may also contribute to the epigenetics of $\mathrm{CHD}$ with recent studies indicating that they are highly susceptible to environmental exposures e.g., cigarette smoking [60,65]. Similarly, through the same physiopathological pathways, maternal diabetes and obesity may induce CHD [61]. However, no study has specifically investigated the role of genetics or epigenetics in the association between SGA and CHD.

Another unresolved issue concerns the role of multiple pregnancies and its possible effect in the association between CHD and SGA. Although, Gijtenbeek et al. found in a systematic review that there is more CHD in twin pregnancies, which in turn are known to have higher rates of SGA [66]. Consequently, the link between multiple pregnancy and advanced maternal on CHD and SGA is unclear because to our knowledge few studies have addressed this issue. The key underlying factor between type of pregnancy and CHD-SGA being the placenta which could have a direct or indirect role in this association [20,67-69]. Jones et al. found a physiopathological explanation of SGA in HLHS based on placental histological analysis, a finding corroborated by other authors specializing in placentology rather than our study question [20]. For example, Matthiesen et al. investigated fetal and placental growth using Z scores [70]. Despite finding a slight difference in placental growth for HLHS, Matthiesen et al. observed an association between suboptimal placental weight and impaired fetal growth for TOF, VSD, and double outlet right ventricle [70]. Consequently, they concluded that placental growth is part of the causal pathway of the association between SGA and certain CHD. In conclusion, from our findings and based the literature, we hypothesize that both placental dysmorphology and abnormal fetal hemodynamics could play a role in the association between CHD and SGA. However further study is required to fully investigate this hypothesis.

This systematic review also confirmed ambiguity in the use of FGR and SGA in the literature. Despite the fact that SGA and FGR are quite distinct concepts, the terms were used interchangeably by different authors using a variety of definitions, cutoff thresholds and reference populations to infer the same meaning; SGA often being used as a proxy for FGR. A recent consensus based definition using a Delphi procedure defined FGR using exclusively ultrasound measurements [71]. While an international meeting of experts in 2007 reached a consensus on SGA, defining it as "a weight and/or 
length less than minus 2 standard deviations from the mean"; confusion still reigns [72,73]. Once our literature review was completed, we found an article that used the term "growth restriction in the newborn (GRN)" aimed at clarifying the situation [74]. This consensus-based definition, defined GRN as "birthweight $<$ 3rd percentile compared to population or customized charts". Alternatively, the presence of three out of the following five criteria: "birthweight $<10$ th percentile compared to population or customized references, head circumference $<10$ th percentile, length $<10$ th percentile, prenatal diagnosis of FGR, and data on maternal pregnancy pathology" [48]. Of the 38 studies included in our systematic review, seven (18.4\%) studies used a definition of SGA as birthweight $<3$ rd percentile thereby conforming to the recent definition of GRN. Although only two studies could be used in the meta-analysis, the proportion of GRN in all CHD was $6 \%$ (95\% CI 6\%-7\%) $[26,39,74]$. However, we were unable to compare this to the proportion of GRN in the general population from the literature as this is a new concept. For the same reason our search did not find any study on CHD that specifically used the term GRN and further studies on this subject is required.

\subsection{Strengths}

Strengths of this systematic review are that a thorough search of the literature was carried out by a multidisciplinary team with specializations in pediatric cardiology, obstetrics, epidemiology, and library science. Following good research practice, the study protocol was registered in the PROSPERO database. The abstracts and articles were reviewed by two independent reviewers and data extraction followed standardized procedures. We evaluated the risk of bias using a validated standardized checklist. The set of studies included in the systematic review and particularly in the meta-analysis included many large population-based studies, which strengthened the external validity of the study in high resource countries. Results highlighted differences in the risk of SGA across different CHD subgroups, which can be useful for risk assessment and for generating hypotheses about the relation between $\mathrm{CHD}$ and growth restriction.

\subsection{Limitations}

Our study has certain limitations and caveats. Differences in practices and policies for prenatal diagnosis and termination of pregnancy for fetal anomaly (TOPFA) across populations and over time can result in changes in the proportion of SGA among newborns with CHD. As TOPFA concerns more severe CHD, all else equal, increases in TOPFA is likely to decrease the proportion of SGA among newborns with CHD. This is more likely to be the case for CHD associated with genetic or other severe anomalies.

The long period of time (1972-2018) for the publications included in the review could have affected the results, in part due to TOPFA but also changes in diagnosis of CHD and the and reference populations used for SGA. However, 2/3 of studies were published after 2009 and the meta-analysis results were often comparable for older and more recent studies.

The paucity of data on isolated subgroups of CHD complicated the interpretation of differences in the proportion of SGA across subgroups of CHD. In addition, the use of large and administrative databases in a number of studies could have been a source of inaccuracies because of coding and data entry errors.

As the majority of studies were from high resource, Western countries, (over two thirds of studies came from the USA), the results may not be generalizable to middle- and low-resource countries.

Finally, we did not evaluate publication bias due to the nature of the research question. Publication bias occurs when negative findings are less likely to be published and can be measured via visual inspection of funnel plots and Egger's test. However, because there are no negative results in a prevalence study, we deemed these methods inappropriate for our meta-analysis [75]. 


\section{Conclusions}

Overall, the proportion of SGA in all CHD (20\%) was 2-fold higher whereas that of isolated CHD $(14 \%)$ was as 1.4-fold higher than the expected proportion in the general population. Although the available data have important limits, differences in the proportion of SGA for different subtypes of CHD suggest that there are different pathophysiological mechanisms underlying the relation between CHD and growth restriction. Further studies are required to disentangle the mechanisms of the association between CHD and growth restriction and the risks associated with growth restriction for newborns with CHD.

Author Contributions: Conceptualization, B.K. and L.J.S.; methodology, A.G., N.D. and N.B.; software, A.G. and N.B.; validation, L.J.S., D.B., and B.K.; formal analysis, A.G., N.D. and N.B.; investigation, A.G. and N.D.; resources, A.G. and N.D.; data curation, A.G. and N.D.; writing-original draft preparation, A.G. and N.D.; writing-review and editing, A.G., N.D., L.J.S., D.B. and B.K.; visualization, B.K.; supervision, B.K.; project administration, B.K.; funding acquisition, A.G. All authors have read and agreed to the published version of the manuscript.

Funding: Thesis project financed by APHP DRCI and Association pour la Recherche en Cardiologie du Foetus à l'Adulte (ARCFA).

Acknowledgments: Catherine Weil.

Conflicts of Interest: The authors declare that they have no conflict of interest.

$\begin{array}{ll}\text { Abbreviations } \\ \text { CHD } & \text { Congenital heart defects } \\ \text { SGA } & \text { Small for gestational age } \\ \text { CASP } & \text { Critical Appraisal Skills Programme } \\ \text { HLHS } & \text { hypoplastic left heart syndrome } \\ \text { ToF } & \text { Tetraology of Fallot } \\ \text { TGV } & \text { transposition of great vessels } \\ \text { VSD } & \text { ventricualar septal defect } \\ \text { CoAo } & \text { coarctation of the aorta } \\ \text { AVSD } & \text { atrioventricular septal defect } \\ \text { TA } & \text { tricuspid atresia } \\ \text { CAT } & \text { common truncus arteriosus }\end{array}$

\section{References}

1. van der Linde, D.; Konings, E.E.; Slager, M.A.; Witsenburg, M.; Helbing, W.A.; Takkenberg, J.J.; Roos-Hesselink, J.W. Birth prevalence of congenital heart disease worldwide: A systematic review and meta-analysis. J. Am. Coll. Cardiol. 2011, 58, 2241-2247. [CrossRef]

2. Zimmerman, M.S.; Smith, A.G.C.; Sable, C.A.; Echko, M.M.; Wilner, L.B.; Olsen, H.E.; Atalay, H.T.; Awasthi, A.; Bhutta, Z.A.; Boucher, J.L.; et al. Global, regional, and national burden of congenital heart disease, 1990-2017: A systematic analysis for the Global Burden of Disease Study 2017. Lancet Child Adolesc. Health 2020, 4, 185-200. [CrossRef]

3. Best, K.E.; Rankin, J. Long-term survival of individuals born with congenital heart disease: A systematic review and meta-analysis. J. Am. Heart Assoc. 2016, 5, e002846. [CrossRef] [PubMed]

4. Liberati, A.; Altman, D.G.; Tetzlaff, J.; Mulrow, C.; Gøtzsche, P.C.; Ioannidis, J.P.; Clarke, M.; Devereaux, P.J.; Kleijnen, J.; Moher, D. The PRISMA statement for reporting systematic reviews and meta-analyses of studies that evaluate health care interventions: Explanation and elaboration. Ann. Intern. Med. 2009, 151, W-65. [CrossRef] [PubMed]

5. Derridj, N.; Khoshnood, B.; Salomon, L.J.; GhanchiI, A. A Systematic Review of the Prevalence of Fetal Growth Restriction (FGR) in Children Born with a Congenital Heart Defect (CHD). PROSPERO 2019 CRD42019131079. Available online: https://www.crd.york.ac.uk/prospero/display_record.php?ID= CRD42019131079 (accessed on 29 March 2020). 
6. Suri, H. Ethical Considerations of Conducting Systematic Reviews in Educational Research; Zawacki-Richter, O., Kerres, M., Bedenlier, S., Bond, M., Buntins, K., Eds.; Systematic Reviews in Educational Research; Springer VS: Wiesbaden, Germany, 2020.

7. Ouzzani, M.; Hammady, H.; Fedorowicz, Z.; Elmagarmid, A. Rayyan-A web and mobile app for systematic reviews. Syst. Rev. 2016, 5, 210. [CrossRef]

8. Critical Appraisal Skills Programme CASP Cohort Study Checklist. Available online: https://casp-uk.net/ wp-content/uploads/2018/01/CASP-Cohort-Study-Checklist_2018.pdf (accessed on 29 March 2020).

9. Ego, A. Definitions: Small for gestational age and intrauterine growth retardation. J. Gynecol. Obstet. Biol. Reprod. 2013, 42, 872-894. [CrossRef]

10. Barendregt, J.J.; Doi, S.A.; Lee, Y.Y.; Norman, R.E.; Vos, T. Meta-analysis of prevalence. J. Epidemiol. Community Health 2013, 67, 974-978. [CrossRef]

11. Nyaga, J.; Muthuri, C.W.; Matiru, V.N.; Jefwa, J.M.; Okoth, S.A.; Wachira, P. Influence of soil fertility amendment practices on ex-situ utilisation of indigenous arbuscular mycorrhizal fungi and performance of maize and common bean in Kenyan highlands. Trop. Subtrop. Agroecosyst. 2014, 17, 129-141.

12. Khoury, M.J.; Erickson, J.D.; Cordero, J.F.; McCarthy, B.J. Congenital malformations and intrauterine growth retardation: A population study. Pediatrics 1988, 82, 83-90.

13. Reynolds, J.L. Intrauterine growth retardation in children with congenital heart disease-Its relation to aortic stenosis. Birth Defects Orig. Artic. Ser. 1972, 8, 143-148.

14. Rosenthal, G.L.; Wilson, P.D.; Permutt, T.; Boughman, J.A.; Ferencz, C. Birth weight and cardiovascular malformations: A population-based study: The Baltimore-Washington infant study. Am. J. Epidemiol. 1991, 133, 1273-1281. [CrossRef] [PubMed]

15. Yu, G.; Mao, L.; Chen, S. Clinical features of early newborn infants with congenital heart disease. Zhonghua Xin Xue Guan Bing Za Zhi 2014, 42, 484-486. [PubMed]

16. Malik, S.; Cleves, M.A.; Zhao, W.; Correa, A.; Hobbs, C.A. Association between congenital heart defects and small for gestational age. Pediatrics 2007, 119, e976-e982. [CrossRef] [PubMed]

17. Nembhard, W.N.; Salemi, J.L.; Hauser, K.W.; Kornosky, J.L. Are there ethnic disparities in risk of preterm birth among infants born with congenital heart defects? Birth Defects Res. Part A: Clin. Mol. Teratol. 2007, 79, 754-764. [CrossRef]

18. Wallenstein, M.B.; Harper, L.M.; Odibo, A.O.; Roehl, K.A.; Longman, R.E.; Macones, G.A.; Cahill, A.G. Fetal congenital heart disease and intrauterine growth restriction: A retrospective cohort study. J. Matern. -Fetal Neonatal Med. 2012, 25, 662-665. [CrossRef]

19. Wollins, D.S.; Ferencz, C.; Boughman, J.A.; Loffredo, C.A. A population-based study of coarctation of the aorta: Comparisons of infants with and without associated ventricular septal defect. Teratology 2001, 64, 229-236. [CrossRef]

20. Jones, H.N.; Olbrych, S.K.; Smith, K.L.; Cnota, J.F.; Habli, M.; Ramos-Gonzales, O.; Owens, K.J.; Hinton, A.C.; Polzin, W.J.; Muglia, L.J.; et al. Hypoplastic left heart syndrome is associated with structural and vascular placental abnormalities and leptin dysregulation. Placenta 2015, 36, 1078-1086. [CrossRef]

21. Li, Y.; Liu, X.H.; Wang, F.Y.; Zhao, X.L.; Zhang, X.; Zhang, Y.P. Analysis of the birth defects among, 61272 live born infants in Beijing. J. Peking Univ. Health Sci. 2009, 41, 414-417.

22. Oyarzún, I.; Claveria, C.; Larios, G.; Le Roy, C. Nutritional recovery after cardiac surgery in children with congenital heart disease. Rev. Chil. Pediatr. 2018, 89, 24-31. [CrossRef]

23. Archer, J.M.; Yeager, S.B.; Kenny, M.J.; Soll, R.F.; Horbar, J.D. Distribution of and mortality from serious congenital heart disease in very low birth weight infants. Pediatrics 2011, 127, 293-299. [CrossRef]

24. Bain, J.; Benjamin, D.K.; Hornik, C.P.; Clark, R.; Smith, P.B. Risk of necrotizing enterocolitis in very-low-birth-weight infants with isolated atrial and ventricular septal defects. J. Perinatol. 2014, 34, 319-321. [CrossRef]

25. Calderon, J.; Willaime, M.; Lelong, N.; Bonnet, D.; Houyel, L.; Ballon, M.; Goffinet, F.; Khoshnood, B. Population-based study of cognitive outcomes in congenital heart defects. Arch. Dis. Child. 2018, 103, 49-56. [CrossRef]

26. Cedergren, M.I.; Källén, B.A. Obstetric outcome of 6346 pregnancies with infants affected by congenital heart defects. Eur. J. Obstet. Gynecol. Reprod. Biol. 2006, 125, 211-216. [CrossRef]

27. Chu, P.Y.; Li, J.S.; Kosinski, A.S.; Hornik, C.P.; Hill, K.D. Epidemiology and Mortality of Very and Extremely Preterm Infants with Congenital Heart Defects. Circulation 2015, 132 (Suppl. 3), A12713. 
28. Cnota, J.F.; Hangge, P.T.; Wang, Y.; Woo, J.G.; Hinton, A.C.; Divanovic, A.A.; Michelfelder, E.C.; Hinton, R.B. Somatic growth trajectory in the fetus with hypoplastic left heart syndrome. Pediatric Res. 2013, 74, $284-289$. [CrossRef]

29. Joelsson, B.M.E.; Sunnegårdh, J.; Hanseus, K.; Berggren, H.; Jonzon, A.; Jögi, P.; Lundell, B. The outcome of children born with pulmonary atresia and intact ventricular septum in Sweden from 1980 to 1999. Scand. Cardiovasc. J. 2001, 35, 192-198.

30. ElHassan, N.O.; Tang, X.; Gossett, J.; Zakaria, D.; Ross, A.; Kona, S.K.; Prodhan, P. Necrotizing enterocolitis in infants with hypoplastic left heart syndrome following stage, 1 palliation or heart transplant. Pediatric Cardiol. 2018, 39, 774-785. [CrossRef]

31. Fisher, J.G.; Bairdain, S.; Sparks, E.A.; Khan, F.A.; Archer, J.M.; Kenny, M.; Edwards, E.M.; Soll, R.F.; Modi, B.P.; Yeager, S.; et al. Serious congenital heart disease and necrotizing enterocolitis in very low birth weight neonates. J. Am. Coll. Surg. 2015, 220, 1018-1026. [CrossRef]

32. Gelehrter, S.; Fifer, C.G.; Armstrong, A.; Hirsch, J.; Gajarski, R. Outcomes of hypoplastic left heart syndrome in low-birth-weight patients. Pediatric Cardiol. 2011, 32, 1175-1181. [CrossRef]

33. Jacobs, E.G.J.; Leung, M.P.; Karlberg, L.J. Birthweight distribution in southern Chinese infants with symptomatic congenital heart disease. J. Paediatr. Child Health 2003, 39, 191-196. [CrossRef]

34. Josefsson, A.; Kernell, K.; Nielsen, N.E.; Bladh, M.; Sydsjö, G. Reproductive patterns and pregnancy outcomes in women with congenital heart disease-A Swedish population-based study. Acta Obstet. Gynecol. Scand. 2011, 90, 659-665. [CrossRef] [PubMed]

35. Karr, S.S.; Brenner, J.I.; Loffredo, C.; Neill, C.A.; Rubin, J.D. Tetralogy of fallot: The spectrum of severity in a regional study 1981-1985. Am. J. Dis. Children 1992, 146, 121-124. [CrossRef] [PubMed]

36. Kernell, K.; Sydsjö, G.; Bladh, M.; Nielsen, N.E.; Josefsson, A. Congenital heart disease in men-birth characteristics and reproduction: A national cohort study. BMC Pregnancy Childbirth 2014, 14, 187. [CrossRef] [PubMed]

37. Kramer, H.H.; Trampisch, H.J.; Rammos, S.; Giese, A. Birth weight of children with congenital heart disease. Eur. J. Pediatrics 1990, 149, 752-757. [CrossRef]

38. Levin, D.L.; Stanger, P.A.U.L.; Kitterman, J.A.; Heymann, M.A. Congenital heart disease in low birth weight infants. Circulation 1975, 52, 500-503. [CrossRef]

39. Levy, R.J.; Rosenthal, A.; Fyler, D.C.; Nadas, A.S. Birthweight of infants with congenital heart disease. Am. J. Dis. Child. 1978, 132, 249-254. [CrossRef]

40. Lupo, P.J.; Langlois, P.H.; Mitchell, L.E. Epidemiology of Ebstein anomaly: Prevalence and patterns in Texas 1999-2005. Am. J. Med. Genet. Part A 2011, 155, 1007-1014. [CrossRef]

41. Nembhard, W.N.; Loscalzo, M.L. Fetal growth among infants with congenital heart defects by maternal race/ethnicity. Ann. Epidemiol. 2009, 19,311-315. [CrossRef]

42. Pappas, A.; Shankaran, S.; Hansen, N.I.; Bell, E.F.; Stoll, B.J.; Laptook, A.R.; Walsh, M.C.; Das, A.; Bara, R.; Hale, E.C.; et al. Outcome of extremely preterm infants $(<1000 \mathrm{~g})$ with congenital heart defects from the National Institute of Child Health and Human Development Neonatal Research Network. Pediatric Cardiol. 2012, 33, 1415-1426.

43. Polito, A.; Piga, S.; Cogo, P.E.; Corchia, C.; Carnielli, V.; Da Frè, M.; Di Lallo, D.; Favia, I.; Gagliardi, L.; Macagno, F.; et al. Increased morbidity and mortality in very preterm/VLBW infants with congenital heart disease. Intensive Care Med. 2013, 39, 1104-1112. [CrossRef]

44. Sochet, A.A.; Ayers, M.; Quezada, E.; Braley, K.; Leshko, J.; Amankwah, E.K.; Quintessenza, J.A.; Jacobs, J.P.; Dadlani, G. The importance of small for gestational age in the risk assessment of infants with critical congenital heart disease. Cardiol. Young 2013, 23, 896-904. [CrossRef] [PubMed]

45. Steurer, M.; Burke, E.; Oltman, S.; Baer, R.; Ryckman, K.; Paynter, R.; Liang, L.; McCarthy, M.; Feuer, S.; Chambers, C.; et al. The Effect of Birth Weight on Mortality in Infants with Critical Congenital Heart Disease. J. Am. Coll. Cardiol. 2018, 71 (Suppl. 11), A629. [CrossRef]

46. Story, L.; Pasupathy, D.; Sankaran, S.; Sharland, G.; Kyle, P. Influence of birthweight on perinatal outcome in fetuses with antenatal diagnosis of congenital heart disease. J. Obstet. Gynaecol. Res. 2015, 41, 896-903. [CrossRef] [PubMed]

47. Swenson, A.W.; Dechert, R.E.; Schumacher, R.E.; Attar, M.A. The effect of late preterm birth on mortality of infants with major congenital heart defects. J. Perinatol. 2012, 32, 51-54. [CrossRef] [PubMed] 
48. Wei, D.; Azen, C.; Bhombal, S.; Hastings, L.; Paquette, L. Congenital heart disease in low-birth-weight infants: Effects of small for gestational age (SGA) status and maturity on postoperative outcomes. Pediatric Cardiol. 2015, 36, 1-7. [CrossRef]

49. Williams, R.V.; Ravishankar, C.; Zak, V.; Evans, F.; Atz, A.M.; Border, W.L.; Levine, J.; Li, J.S.; Mahony, L.; Mital, S.; et al. Birth weight and prematurity in infants with single ventricle physiology: Pediatric heart network infant single ventricle trial screened population. Congenit. Heart Dis. 2010, 5, 96-103. [CrossRef]

50. Gaudineau, A. Prevalence, risk factors, maternal and fetal morbidity and mortality of intrauterine growth restriction and small-for-gestational age. J. Gynecol. Obstet. Biol. Reprod. 2013, 42, 895-910. [CrossRef]

51. Miller, S.L.; Huppi, P.S.; Mallard, C. The consequences of fetal growth restriction on brain structure and neurodevelopmental outcome. J. Physiol. 2016, 594, 807-823. [CrossRef]

52. Suhag, A.; Berghella, V. Intrauterine growth restriction (IUGR): Etiology and diagnosis. Curr. Obstet. Gynecol. Rep. 2013, 2, 102-111. [CrossRef]

53. Blue, G.M.; Kirk, E.P.; Sholler, G.F.; Harvey, R.P.; Winlaw, D.S. Congenital heart disease: Current knowledge about causes and inheritance. Med. J. Aust. 2012, 197, 155-159. [CrossRef]

54. Puccio, G.; Giuffré, M.; Piccione, M.; Piro, E.; Rinaudo, G.; Corsello, G. Intrauterine growth restriction and congenital malformations: A retrospective epidemiological study. Ital. J. Pediatrics 2013, 39, 23. [CrossRef] [PubMed]

55. Sun, L.; Macgowan, C.K.; Sled, J.G.; Yoo, S.J.; Manlhiot, C.; Porayette, P.; Grosse-Wortmann, L.; Jaeggi, E.; McCrindle, B.W.; Kingdom, J.; et al. Reduced fetal cerebral oxygen consumption is associated with smaller brain size in fetuses with congenital heart disease. Circulation 2015, 131, 1313-1323. [CrossRef] [PubMed]

56. Malik, S.; Cleves, M.A.; Honein, M.A.; Romitti, P.A.; Botto, L.D.; Yang, S.; Hobbs, C.A. Maternal smoking and congenital heart defects. Pediatrics 2008, 121, e810-e816. [CrossRef] [PubMed]

57. Hall, M.E.; Harmancey, R.; Stec, D.E. Lean heart: Role of leptin in cardiac hypertrophy and metabolism. World J. Cardiol. 2015, 7, 511. [CrossRef] [PubMed]

58. Spiers, P.S. Does growth retardation predispose the fetus to congenital malformation? Lancet 1982, 319, 312-314. [CrossRef]

59. Schulkey, C.E.; Regmi, S.D.; Magnan, R.A.; Danzo, M.T.; Luther, H.; Hutchinson, A.K.; Panzer, A.A.; Grady, M.M.; Wilson, D.B.; Jay, P.Y. The maternal-age-associated risk of congenital heart disease is modifiable. Nature 2015, 520, 230-233. [CrossRef]

60. Fung, A.; Manlhiot, C.; Naik, S.; Rosenberg, H.; Smythe, J.; Lougheed, J.; Mondal, T.; Chitayat, D.; McCrindle, B.W.; Mital, S. Impact of prenatal risk factors on congenital heart disease in the current era. J. Am. Heart Assoc. 2013, 2, e000064. [CrossRef]

61. Vecoli, C.; Pulignani, S.; Foffa, I.; Grazia Andreassi, M. Congenital heart disease: The crossroads of genetics, epigenetics and environment. Curr. Genom. 2014, 15, 390-399. [CrossRef]

62. Chowdhury, S.; Cleves, M.A.; MacLeod, S.L.; James, S.J.; Zhao, W.; Hobbs, C.A. Maternal DNA hypomethylation and congenital heart defects. Birth Defects Res. Part A: Clin. Mol. Teratol. 2011, 91, 69-76. [CrossRef]

63. Digilio, M.C.; Marino, B. What is new in genetics of congenital heart defects? Front. Pediatrics 2016, 4, 120. [CrossRef]

64. Monteagudo-Sánchez, A.; Sánchez-Delgado, M.; Mora, J.R.H.; Santamaría, N.T.; Gratacós, E.; Esteller, M.; de Heredia, M.L.; Nunes, V.; Choux, C.; Fauque, P.; et al. Differences in expression rather than methylation at placenta-specific imprinted loci is associated with intrauterine growth restriction. Clin. Epigenetics 2019, 11, 35. [CrossRef] [PubMed]

65. Moore-Morris, T.; van Vliet, P.P.; Andelfinger, G.; Puceat, M. Role of epigenetics in cardiac development and congenital diseases. Physiol. Rev. 2018, 98, 2453-2475. [CrossRef] [PubMed]

66. Gijtenbeek, M.; Shirzada, M.R.; Ten Harkel, A.D.; Oepkes, D.; C Haak, M. Congenital heart defects in monochorionic twins: A systematic review and meta-analysis. J. Clin. Med. 2019, 8, 902. [CrossRef] [PubMed]

67. Barber, E.; Weiner, E.; Feldstein, O.; Dekalo, A.; Mizrachi, Y.; Gonullu, D.C.; Bar, J.; Schreiber, L.; Kovo, M. The differences in placental pathology and neonatal outcome in singleton vs. twin gestation complicated by small for gestational age. Arch. Gynecol. Obstet. 2018, 298, 1107-1114. [CrossRef] 
68. Grantz, K.L.; Grewal, J.; Albert, P.S.; Wapner, R.; D’Alton, M.E.; Sciscione, A.; Grobman, W.A.; Wing, D.A.; Owen, J.; Newman, R.B.; et al. Dichorionic twin trajectories: The NICHD fetal growth studies. Am. J. Obstet. Gynecol. 2016, 215, 221.E1-221.E16. [CrossRef]

69. Kibel, M.; Kahn, M.; Sherman, C.; Kingdom, J.; Zaltz, A.; Barrett, J.; Melamed, N. Placental abnormalities differ between small for gestational age fetuses in dichorionic twin and singleton pregnancies. Placenta 2017, 60, 28-35. [CrossRef]

70. Matthiesen, N.B.; Henriksen, T.B.; Gaynor, J.W.; Agergaard, P.; Bach, C.C.; Hjortdal, V.E.; Østergaard, J.R. Congenital heart defects and indices of fetal cerebral growth in a nationwide cohort of 924422 liveborn infants. Circulation 2016, 133, 566-575.

71. Gordijn, S.J.; Beune, I.M.; Thilaganathan, B.; Papageorghiou, A.; Baschat, A.A.; Baker, P.N.; Silver, R.M.; Wynia, K.; Ganzevoort, W. Consensus definition of fetal growth restriction: A Delphi procedure. Ultrasound Obstet. Gynecol. 2016, 48, 333-339. [CrossRef]

72. Clayton, P.E.; Cianfarani, S.; Czernichow, P.; Johannsson, G.; Rapaport, R.; Rogol, A. Management of the child born small for gestational age through to adulthood: A consensus statement of the International Societies of Pediatric Endocrinology and the Growth Hormone Research Society. J. Clin. Endocrinol. Metab. 2007, 92, 804-810. [CrossRef]

73. Zeve, D.; Regelmann, M.O.; Holzman, I.R.; Rapaport, R. Small at birth, but how small? The definition of SGA revisited. Horm. Res. Paediatr. 2016, 86, 357-360. [CrossRef]

74. Beune, I.M.; Bloomfield, F.H.; Ganzevoort, W.; Embleton, N.D.; Rozance, P.J.; van Wassenaer-Leemhuis, A.G.; Wynia, K.; Gordijn, S.J. Consensus based definition of growth restriction in the newborn. J. Pediatrics 2018, 196, 71-76. [CrossRef] [PubMed]

75. Hunter, J.P.; Saratzis, A.; Sutton, A.J.; Boucher, R.H.; Sayers, R.D.; Bown, M.J. In meta-analyses of proportion studies, funnel plots were found to be an inaccurate method of assessing publication bias. J. Clin. Epidemiol. 2014, 67, 897-903. [CrossRef] [PubMed]

(C) 2020 by the authors. Licensee MDPI, Basel, Switzerland. This article is an open access article distributed under the terms and conditions of the Creative Commons Attribution (CC BY) license (http://creativecommons.org/licenses/by/4.0/). 